\title{
The Institutional Dynamics of Sharing Biological Information : Towards Reflexive Governance of the Information Society ${ }^{1}$
}

\author{
Tom Dedeurwaerdere \\ Centre for Philosophy of law - Faculty of Philosophy \\ FNRS - University of Louvain (Belgium) \\ dedeurwaerdere@,cpdr.ucl.ac.be
}

\begin{abstract}
The aim of this paper is to contribute to building a framework for reflexive governance of the information society. The hypothesis is that new institutional economics as an interdisciplinary research program can provide some of the necessary tools for this framework and help us to understand how the reflexive feedback of actors and users on the social challenges of the new technologies can be embedded in the institutions of regulation. To test this hypothesis, we develop a specific case study on the building of the microbiological commons. This case study is chosen because of the leading role of this field in the development of institutions procedures for reflexive involvement of actors and users in the institutional design, such as in the case of the Global Biodiversity Information Facility or GENBANK. As our analysis attempts to show, the success of these initiatives in building both efficient and legitimate means of information sharing is dependent on a double reflexive mechanism embedded in the institutional rules : (1) organizing feedback of the actors and users on the institutional rules and (2) the building of common understanding amongst different stakeholder communities.
\end{abstract}

Keywords: Reflexive governance, Genetic resources, Databases, Intellectual property rights, Public goods.

1 This paper is a reworked version of two forthcoming publications Dedeurwaerdere 2006a and $2006 \mathrm{~b}$.

Please use the following forma when citing this chapter:

Dedeurwacrdere, T., 2007, in II:LP International Federation for Information Processing, Volume 233, The Infornation Society: Innovations, I.egitimacy, Bthics and Democracy, cds. P. Goution, Lavelle, S., Ducuenoy, P., Kimppa, K., I.aurent, V., (Broston: Springer), pp. 12I-146. 


\section{Introduction}

As scientists and user groups become better connected with each other (particularly through the Internet), and as research focuses on issues of global importance (such as climate change, human health and biodiversity) there is a growing need to systematically address data access and sharing issues beyond national jurisdictions and thereby create greater value from international cooperation. The goal should be to ensure that both researchers and the broader public receive the optimum return on public investment, and to build on the value chain of investment in research and research data (Stiglitz et al. 2000).

Integrated and combined access to this multifaceted realm of information opens perspectives for the implementation of new applications. In the field of the life sciences, new sets of tools for studying biological building blocks and pathways will lay the foundation for even more complex future projects. These may include the complete mapping of an organism's protein and metabolism networks, as well as the creation of biological models that can pave the way for theoretical models on bacterial speciation and its complex ecological dynamics (Gevers et al. submitted), or the development of tools for automated species identification. These tools undoubtedly require access to sets of skills that are not typically encountered among systematists or within the departments and institutions in which the bulk of formal taxonomic identifications are conducted. Developing solid approaches requires new collaborations between microbiologists, engineers, mathematicians, computer scientists and people who have significant knowledge of the legal and socioeconomic aspects of sharing biological resources and software tools in the public domain.

These new applications of information technologies within the life sciences raise important questions related to the social embedding of information technologies. Hence it raises important new questions for the field of 'social informatics' (Kling, 1996). Indeed technical choices within the field of bioinformatics also depend on social choices, whether it is in problems such as the building of genomic sequence databases, the design of persistent numerical identifiers for taxonomic information of living organisms or the integration of clinical data and images coming brain research. These technological developments reflect social choices on issues such as protection of privacy, ownership of life or bioethics. Moreover, the capacity to make these choices depends increasingly on the possibility to retain certain property rights on this information, which define who has the right to decide upon the way information is used, managed and exchanged. Open access to the information and shared ownership of the information has become a key condition for connecting the path of development of information technologies in the life sciences to social values and ethical reflection.

Within the field of the life sciences, initiatives for sharing information through networking distributed databases have emerged, operating both on a global scale (such as the consortium for Common Access to Biological Resources and Information (CABRI), connecting world wide microbiological resources) and in 
more focused networks (such as the European Human Frozen Tumour Tissue Databank (TuBaFrost)). From a governance perspective, these networks face increasing pressure from the development of global markets. In particular, the introduction of new standards of intellectual property protection during the last twenty years has had a profound impact on the sharing of data and resources in the field of the life sciences. Two of the most influential and widely debated changes in this context are the 1980 Bayh-Dole Act in the US (Rai and Eisenberg 2003) and, more recently, the 1996 EU database directive 96/9/EC (Reichman and Uhlir 1999). The Bayh-Dole act explicitly gave universities the right to seek patent protection on the results of government sponsored research and to retain patent ownership. As a consequence, in the period from 1980 to 1992 , the number of patents granted per year to universities in the US increased from fewer than 250 to almost 2700 (Rai 1999 , p.109). The EC database directive $96 / 9 / \mathrm{EC}$ was a landmark decision that lowered the standards of eligibility to database protection. Indeed the database directive offered copyright protection to databases that were original in the selection or the arrangement of their contents, but also to non-original databases if it could be shown that there had been a substantial investment in either the obtaining, the verification or the presentation of their contents. This extended protection to library catalogues for instance, but also to biological information facilities that network existing databases.

These rulings have to be situated within the wider phenomenon of the globalisation of intellectual property rights that has accompanied the genomic revolution in the life sciences and the digital revolution in information technologies. This new context has played a key role in stimulating innovation and new market developments in the life sciences. However, it is also posing a challenge to lifescience research for public purposes, as the research communities have to adapt their strategies and design new institutional arrangements to allow them to provide services of general interest in an increasingly competitive and international environment.

In this paper, I will analyse the models for the institutional design of information sharing in the context of global intellectual property rights. In particular, I will rely on contemporary insights from new institutional economics that show the necessity of developing new forms of collective action to deal both with the insufficiencies of market solutions and the limits of the new forms of public regulation, in the context of the construction of a research commons for scientific data (Reichman and Uhlir 2003, Hess and Ostrom 2003, 2005a). Even though a purely economic interpretation of these propositions is possible (ie as a mechanism to cope with market externalities and to economize on transaction costs), we would like to focus on their contribution to a more reflexive construction of the information society. From that point of view, the accent will be on the reflexive role of these collaborative arrangements, as a second order mechanism contributing to the building of common understandings and strategies amongst the actors and the users of the new technologies. This notion of reflexivity is an extension to the field of the Internet of the conception developed by Ulrich Beck in his analysis of the reflexive evolution of technical modernisation. In his sense, "reflexive" does not only mean the way in which the social context of an activity (here the new social challenges raised by the developments in genomics and 
information technologies) has an effect in return on this same activity, but also, as it is the case with U. Beck's notion of "reflexive modernisation", the way in which this "reflexive feedback" can cause a reconfiguration of the normative orientations and cognitive background beliefs that guide the actors and institutions (Beck, 1997 : pp. 11-19). So the focus is both on the feedback of the actors in the different specific actor settings and on the building of common background beliefs and understandings across the specific actor communities. Our contribution to the study of reflexive processes in this paper is to contribute to the institutional design of reflexive governance in the field of the information society through a specific case study in the field of microbiology.

In the rest of this paper I build upon the proposals for information sharing in order to elaborate a framework for the analysis of institutional choice in the field of the microbiological information commons. In the first part I develop a model to describe the transaction situation and then discuss different institutional solutions that have been proposed to cope in a cost-effective manner with the incentive problems in the field of micro-organisms ${ }^{2}$. In the second part I argue that it is necessary to complete this analysis of "optimal institutional design", which favours economic incentives through the allocation of intellectual property rights, with an analysis of the institutional dynamics which takes in to account the reflexivity of the actors and the users on the new technologies.

\section{Setting the stage: the transaction situation and governance models}

Data sharing of microbiological information is essential for the quick translation of research results into knowledge, products and procedures and to improve matters of general interest such as the sustainable use and conservation of biodiversity. At present the widespread national, international and cross-disciplinary sharing of research data is not merely a technological matter, but also a complex social process in which researchers have to balance different pressures and interests. Purely regulatory approaches to data sharing are not likely to be successful without consideration of these factors, as technology itself will not fulfil the promise of escience. Information and communication technologies provide the physical infrastructure. It is up to national governments, international agencies, research institutions and scientists themselves to ensure that the institutional, economic, legal, cultural and behavioural aspects of data sharing are taken into account (Arzberger et al. 2004).

The key players, providing the infrastructure for the sharing of microbiological information, are the organisers of the biobanks and culture collections, who organise the collection, conservation, curation and exchange of biological resources and

2 The world of micro-organisms, or microscopic organisms, includes bacteria and archaea, yeast and fungi, and unicellular animals (protista). In practice however, the term microorganism also refers to microscopic parts of organisms, such as plasmids, phages, DNA probes, plant cells and viruses, and animal and human cell lines. 
related data. Those collections are an outgrowth from the conventional pre-genomics ex situ collections of biological materials that have progressively developed into multi-service facilities called biological resource centres (BRCs). The concept of BRCs was proposed in an influential OECD report in 2001, which defines them as 'service providers and repositories of the living cells and genomes of organisms, and information relating to heredity and the functions of biological systems' (OECD 2001 , p. 11). As such, BRCs contain 'collections of culturable organisms (e.g. microorganisms, plant, animal and human cells), replicable parts of these (e.g. genomes, plasmids, viruses, cDNAs), viable but not yet culturable organisms, cells and tissues, as well as databases containing molecular, physiological and structural information relevant to these collections and related bioinformatics' (ibid.). While a BRC is a collection of resources from any origin, including human, the term 'biobank' refers more particularly to organised collections of biological samples of human origin and the data associated with them ${ }^{3}$. Like BRCs, biobanks come in many different forms, according to the type of samples that are stored and the domain in which they are collected.

Many different initiatives for sharing knowledge through databases, which gather knowledge from different fields of microbiology, exist. These include the CABRI and TuBaFrost networks mentioned in the introduction, and the ongoing Global Biodiversity Information Facility (GBIF) project ${ }^{4}$. These networks face increasing pressure from the development of global intellectual property rights, which has lead to competition for the ownership of previously shared resources. At the same time, the role of the state in the provision of services of general interest, such as public collections and databases, is gradually shifting from direct intervention to regulation of markets or quasi-markets. In the context of this new situation, cost effective access can, for example, be guaranteed by the state by the introduction of a general research exemption for database access for non-commercial research. In a similar manner, the exchange of biological material can be regulated through compulsory clauses in the contractual arrangements for the exchange of biological material, specifying the origin of the resource and/or prior informed consent.

From an economic point of view, microbiological information has been characterised as being part of the public domain (Oldham 2004, p.59, Williamson 1998, pp.9-11, Smith et al. 2004), implying appropriate public and regulatory institutions for guaranteeing its provision. However, this characterisation is very broad and, as has been shown in recent research (Kaul et al. 2003), the notion of the public domain covers a heterogeneous set of transaction situations and incentive problems, which demands a more fine grained approach.

For these reasons I will focus on the following questions:

3 There are, for example, many facilities in the field of cancer research that initially only conserved cancer cell lines, but which have reorganised themselves as integrated service providers on the BRC model . A good example of such a reform is the European network of blood cord facilities coordinated by Prof. Paolo Rebulla at the Ospedale Maggiore in Milan.

$4 \mathrm{cf}$. www.cabri.org and www.gbif.org 
(1) Wht are the characteristics of the good that is exchanged and the related incentive problems for the provision and use of this good (Section 2.1.)?

(2) What institutional solutions for dealing with these complex incentive problems are currently being proposed (Section 2.2 .)?

\subsection{Microbiological information as a common pool resource}

In general, goods that fall into the public domain - or what is often called in the legal literature the 'commons' (Lessig 1999, Benkler 1998) - are characterised by nonexclusiveness in consumption (Kaul et al. 2003, p.79). This means that the public domain covers a broad set of phenomena where multiple users share a resource in some way (Hess and Ostrom 2005a, p.1). A useful distinction in this broad category of the commons, allowing a better understanding of the incentives that lead to practices of information sharing, is the distinction between public goods and common pool resources. Both are characterised by non-exclusiveness and hence sharing of resources. However, for public goods, the consumption of the resource by one does not diminish the possibilities of consumption by others. Paradigmatic examples are mathematical formulae, new ideas, technical standards or virtually unlimited natural resources such as the light of the sun. In contrast, in the case of common pool resources, the resource is available to all, but one person's benefit subtracts from the products available to others. This is typically the case for depletable resources such as forests, nature parks and clean air.

Individuals involved in the production of public goods face the problems of potentially perverse incentives related to the production process, such as the presence of people benefiting from a public good who have not contributed to its production (Hess and Ostrom 2005a, pp.3-5). For common pool resources, however, since subtractability applies, potentially perverse incentives exist both on the production and the consumption or use side (ibid., p.3). For instance, all common pool resources are exposed to the risk of 'overharvesting' and pollution of the resource.

The microbiological information that is managed and exchanged through BRCs or global information facilities such as GBIF shows characteristics of both public goods and common pool resources. In Table 1, I have illustrated this distinction and the related incentive problems for three components of the knowledge commons: information as a non-physical flow unit that is exchanged within the collaborative networks; the physical flow units or artefacts through which the information is exchanged; and the resource system or facility storing the ideas and the artefacts (Hess and Ostrom 2003, pp.128-130). 
The Institutional Dynamics of Sharing Biological

\begin{tabular}{|c|c|c|c|}
\hline & Information facility & Information flow & $\begin{array}{l}\text { Physical storage } \\
\text { system }\end{array}$ \\
\hline $\begin{array}{l}\text { Type } \\
\text { good }\end{array}$ & Public good & $\begin{array}{l}\text { Common } \\
\text { resource }\end{array}$ & $\begin{array}{l}\text { Common pool } \\
\text { resource }\end{array}$ \\
\hline Example & $\begin{array}{l}\text { Contribution of } \\
\text { information to a } \\
\text { global biological } \\
\text { information archive }\end{array}$ & $\begin{array}{l}\text { Participation in the } \\
\text { exchange of tumour } \\
\text { tissue data }\end{array}$ & $\begin{array}{l}\text { Common web server } \\
\text { for storing images }\end{array}$ \\
\hline $\begin{array}{l}\text { Positive } \\
\text { incentives }\end{array}$ & $\begin{array}{ll}\text { Visibility, } & \text { public } \\
\text { recognition, } & \text { instant } \\
\text { publication } & \end{array}$ & $\begin{array}{l}\text { Access to first-hand, } \\
\text { high-quality } \\
\text { information related } \\
\text { to the data }\end{array}$ & $\begin{array}{l}\text { On line verification } \\
\text { of the diagnosis }\end{array}$ \\
\hline $\begin{array}{l}\text { Perverse } \\
\text { incentives }\end{array}$ & $\begin{array}{l}\text { Under-use: low } \\
\text { visibility, lack of use }\end{array}$ & $\begin{array}{l}\text { Misuse: use of the } \\
\text { data without } \\
\text { contributing to the } \\
\text { flow, plagiarism, } \\
\text { submitting low } \\
\text { quality data }\end{array}$ & $\begin{array}{l}\text { Pollution: storing } \\
\text { redundant } \\
\text { information that } \\
\text { takes a lot of } \\
\text { memory space }\end{array}$ \\
\hline
\end{tabular}

Table 1: Incentive problems for the public good and common pool resource aspects of the microbiological information commons ${ }^{5}$

First, information as a non-material good stored in a facility clearly has the characteristics of a public good. It is a resource shared by multiple individuals in a non-exclusive way and it is non-depletable. The use of an idea by someone does not subtract from the capability of another individual to use the same idea at the same time. As such, in a similar manner to the self-archiving initiatives in the field of scholarly communications (Hess and Ostrom 2003, p.143), researchers who participate in building global biological information facilities are building a universal public good for which the more people who have access, the greater the benefit to everyone ( ibid.). Positive incentives that play a role in self-archiving initiatives, such as the reduction in costs of publication and access, the scientific recognition and credibility that comes with public disclosure, the increased visibility of information, and instant publication and dissemination (Hess and Ostrom 2005a, p.5), have also been documented in the field of the microbiological information commons (Rai 1999, pp.92-95).

Second, information as a non-physical flow unit has also been characterised as a depletable resource and hence presents the characteristics of a common pool resource. Indeed, the value of information to users is not only related to the

5 Examples adapted from Hess and Ostrom (2005b), Table 1. For simplicity of presentation I have merged production and use incentives. 
opportunities they have to access a stock or pool of accumulated knowledge somewhere in an encyclopaedia or digital repository, but also to the quality of the flow of the information. By exchanging the information, it is consumed, verified, completed and interlinked with other information. It is this complex process of exchange and quality management that makes the information valuable to the users of the common knowledge pool. Sustainable management of this flow depends on compliance with a set of rules, such as verification of the quality of information submitted to the common pool, appropriate citation of the source of the information, and cross-linking to the information generated by the users' communities in the field of knowledge concerned. Non-compliance with or violation of these rules harms the common knowledge base and can lead to the information flow drying up. The distinction between the stock of information and the flow is crucial in discussing the microbiological information commons, because of the increasing role of databases as a flow resource in the organisation of information exchanges.

As has been argued by Reichman in his work on database policies, the information contained in databases is both the input of the knowledge generation processes in the information economy and the output of former knowledge generation and innovation processes (Reichman 2002). Moreover, the use of the information in the microbiological commons often depends either on the possibility of linking databases back to 'local knowledge' (for instance knowledge about the behavioural properties of a resource in the environment or the laboratory) or, conversely, of testing a possible innovation path by confronting it with the downstream user communities.

Third, as mentioned above, sharing microbiological information through microbiological information facilities is a complex endeavour that also involves sharing physical flow units and information technologies. For example, providing taxonomic or genetic data to a common database such as GBIF requires the use of a common data format, at the level of both the encoding formats and the transmission protocols. These common formats and protocols depend in turn on the design and permanent evolution of appropriate software, specific to the common knowledge pool. Other non-exclusive resources that play an important role in the microbiological information commons are standardised technologies for the identification of biological resources and numerical identifiers for the persistent identification of the data throughout the process of data exchange with different user communities. Some of these resources (such as common standards) are nondepletable in nature, and can appropriately be described as public goods. Others (such as the bandwidth of the transmission infrastructure or the memory space on a common database webserver) are depletable, and should be considered as common pool resources.

To illustrate some of the incentive problems associated with the microbiological information commons as a common pool resource it is interesting to consider a concrete example, the TuBaFrost network ${ }^{6}$. This gathers data on high quality frozen tumour tissue samples with an accurate diagnosis, which are stored in major European cancer centres and universities, and makes it accessible and searchable through an uncomplicated query system on the Internet. The TuBaFrost database is 
published in the restricted public domain. That means that the project portal can be accessed without restriction, and that access to the search engine of the database is open to all users, on the condition that they register with the website. Control of misuse of the information is carried out through the registration protocol: anyone can register through a simple web-interface, if they provide their name, e-mail and the reason why they want to use the database. This allows ex ante verification of the users intentions and, by keeping track of the identity profiles, ex post control of misuse. Access to other tools, such as self-archiving and the exchange of tumour tissues, is reserved for full participants in the project.

One of the positive incentives for becoming a full participant in the production side is indirect. Through being involved in the generation of high quality information on tumour tissue samples, the partners expect to have first-hand access to a good flow of information from the data in question ${ }^{7}$. A key physical resource that is shared in the TuBaFrost project is the Nanozoomer, which allows representative histology images to be stored in a central database, enlarged $20 \mathrm{x}$ or $40 \mathrm{x}$ and accessed through the virtual tumour bank. The advantage is that, through the addition of images to the virtual tumour bank, diagnoses can be verified on line. However, this also creates a depletable resource to be shared, the disk space of the central database. Because of these different layers of resources to be shared, the organisation of the TuBaFrost network depends on the solution of a complex incentive problem. This involves both pure public goods (such as the information that is contributed to the stock of common knowledge) and common pool resources (such as the self-archiving facility and the Nanozoomer).

\subsection{Institutional solutions to the incentive problems}

In the previous section I discussed the perverse incentives involved in data sharing in the microbiological commons. In this section, I will analyse some of the collective arrangements that are currently being considered for organising data sharing in the microbiological commons, focusing more particularly on the role of property rights and contractual arrangements.

Institutional economics has clarified the role of well-defined property rights in helping to reinforce a long term perspective in the management of a resource and in stimulating investment in the design of institutional rules that can cope with incentive problems (Schlager and Ostrom 1993, Demsetz 1967). However, it is important to qualify this statement.

7 Conversation with the project coordinator, Peter Riegman. 


\begin{tabular}{|l|l|}
\hline 1. Access & $\begin{array}{l}\text { The right to enter a defined physical area and enjoy non- } \\
\text { subtractive benefits }\end{array}$ \\
\hline 2. Contribution & The right to contribute to the content \\
\hline 3. Extraction & $\begin{array}{l}\text { The right to obtain resource units or products of a resource } \\
\text { system }\end{array}$ \\
\hline 4. Removal & The right to remove one's artefacts from the resource \\
\hline $\begin{array}{l}\text { 5.Management/ } \\
\text { participation }\end{array}$ & $\begin{array}{l}\text { The right to regulate internal use patterns and transform } \\
\text { the resource by making improvements }\end{array}$ \\
\hline 6.Exclusion & $\begin{array}{l}\text { The right to determine who will have access, contribution, } \\
\text { extraction, and removal rights and how those rights may } \\
\text { be transferred }\end{array}$ \\
\hline 7.Alienation & \begin{tabular}{l} 
The right to sell or lease management and exclusion rights \\
\hline
\end{tabular}
\end{tabular}

Table 2: The bundle of rights in the digital knowledge commons

Numbers 1-4 are operational rights, numbers 5-7 collective choice rights. Source: Hess and Ostrom (2005a, p.14-15). Full ownership is only acquired by the possession of the full bundle of seven major property rights, which includes the right of alienation of the resource.

Firstly, well-defined property rights do not necessarily imply full ownership, nor a fortiori private ownership. As has been shown, well-defined rights to a good, such as a natural resource, can, for example, include exclusion and management rights attributed to a private organisation, while the resource itself remains in state ownership. In a similar way, data sharing through a data portal can imply the exercise of management and exclusion rights by an organisation, without the full ownership of the original databases necessarily being transferred to this entity. This is the reason that economists have analysed property rights as a 'bundle' of use and decision rights attributed to certain economic agents. Such a bundle of rights specifies a set of operational rights (the use that can be made of a resource) and a set of collective choice rights (who can decide on the future exercise of the rights over the resource). In their framework article, Hess and Ostrom (2005a) distinguish seven major types of property rights that are relevant for the digital knowledge commons (see Table 2).

Second, from the point of view of new institutional economics, property rights are considered in relation to the outcomes that result from the attribution of these rights to certain economic agents in a specific domain and a certain action situation. In particular, these outcomes depend on the effective institutional rules that are defined and enforced by the agents who exercise these rights. Property rights as such only authorise particular actions, but they still need a set of workable institutions to make them effective in a particular situation. The consequences of a set of property rights will hence depend on the cost and availability of institutional arrangements 
that specify the exercise of the rights and the impact of the institutional arrangements on the actors' behaviour.

For instance, in many cases of exclusive-use goods, the exercise of private property rights has led to the most efficient outcomes. However in other cases, the costs implied in the exercise of private property rights (such as the creation and enforcement of rules for market exchange and contractual arrangements) can be too high and have to be balanced against alternative institutional rules and property regimes. Most importantly, this means that no 'one size fits all' property rights regime can be found.

In the field of microbiological commons, three main institutional solutions are discussed in the literature: a model of free dissemination and two models based on conditional deposits for commercial and non-commercial use. All three are based on a form of decentralised ownership and include a certain level of collective management and exclusion rights. Such an institutional arrangement for the governance of the information flow is in accordance with the results that have been obtained from case studies within the field of natural resource management. Indeed, these studies show that in order to deal with collective action problems within a common pool resource, there have to be common rules, at least for exclusion and management. These rules are necessary in order to delimit the boundaries of the common pool and impose graduated sanctions for non-compliance with the rules of use so as to prevent depletion of the resource.

\subsubsection{Facilitating free dissemination with decentralised ownership}

In a first model of data sharing, ownership - and hence the right to alienation remains with the individual data providers. However the providers transfer a part of their management and exclusion rights to a common data portal. Some key features of this first model can be analysed through the example of the Global Biodiversity Facility (GBIF). In the GBIF, data is provided to a collaborative database from a variety of sources; the database in turn makes the data freely available to noncommercial users, as illustrated in Figure 1. The ownership of the data, and any related conditions on the use of the data, remain with the original providers. This means that GBIF does not assert any intellectual property rights to the data that is made available through its network. Moreover, all the data is made available on the terms and conditions that data providers have identified in the metadata. However, even if GBIF does not assert any ownership rights, each data provider transfers some of the management and exclusion rights to GBIF as specified in the Memorandum of Understanding establishing the organisation. This transfer agreement allows different incentive problems related to the governance of the information flow as a common pool resource to be dealt with:

When registering their services with GBIF, the data provider has to sign the GBIF data sharing agreement. This stipulates that the data provider will make reasonable efforts to ensure that the data are accurate and will include a stable and unique identifier with the data (Articles 1.4. and 1.5. of the Data Sharing Agreement). 
The data provider has to be endorsed by a GBIF participant. GBIF participants are the signatories of the GBIF-establishing Memorandum of Understanding. Data participants maintain stable computer gateways (the data nodes) that make data available through the GBIF network. The GBIF participants maintain services that enable new and existing data providers in their domain to be integrated within the GBIF network (Articles 1.8. and 2.4. of the Data Sharing Agreement).

The GBIF participants empower the GBIF secretariat to enter into contracts, execute the work programme and maintain central services for the GBIF network. In particular, the GBIF secretariat may provide full or partial data to other users, together with the terms and conditions for use set by the data provider (Article 1.7. of the Data Sharing Agreement).

Using data through the GBIF network requires agreement to a Data Use Agreement when accessing the search engine. This agreement stipulates that users must publicly acknowledge the data providers whose biodiversity data they have used (Article 1.4. of the Data Use Agreement).

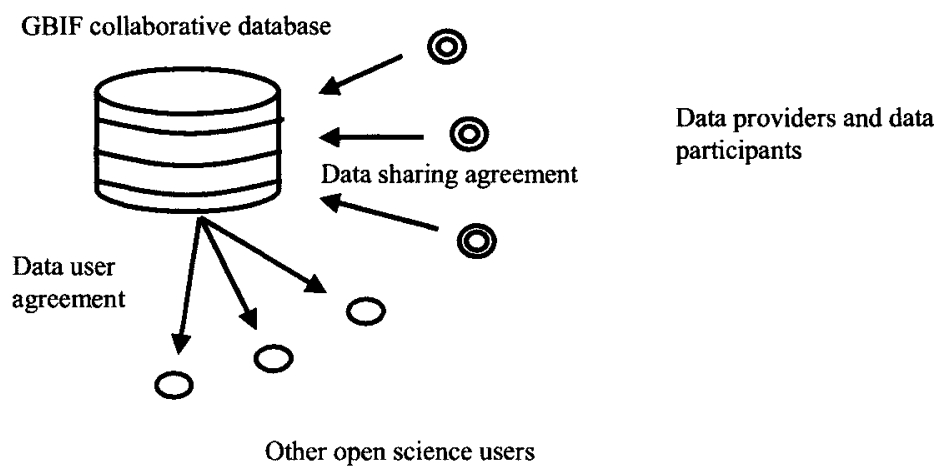

Figure 1: The GBIF model of data sharing (figure of the author)

Through this collective arrangement, GBIF facilitates the free dissemination of biodiversity related data. In practice, GBIF pools data that is, in most cases, already in the public domain or that has been commissioned explicitly for public purposes and can receive a wider audience by being accessible through the data portal. Elsewhere, more sophisticated two-tiered models have been developed to satisfy both public research interests and commercial opportunities.

\subsubsection{Organising the licensing of data through a collective license organisation}

The GBIF model is probably not appropriate for all types of microbiological data sharing. Indeed GBIF focuses on biodiversity related data (including substantial 
microbiological databases) but not on the wealth of microbiological data that is relevant for research but not directly relevant for biodiversity conservation purposes (such as plasmids, viruses or human cell lines for cancer research).

Moreover, certain types of data are relevant both for public research purposes and private R\&D and would benefit from a more coordinated approach to the conditions of data licensing to commercial partners.

The report of an OECD working group on data sharing in neuroinformatics states some of the conditions under which a more stringent coordination of the conditions for commercial and non-commercial use of the database is called for. Indeed, for public domain databases and/or in the absence of collective management of the conditions of follow-on use, data sharing does not always guarantee credit to the researchers who originally produced the data, nor provide them with any reward if extensions to their work are commercialised (Eckersley et al. 2003, p.155). Moreover, it only provides weak protection against the broader problem of 'patent thickets' (ibid., p.156).

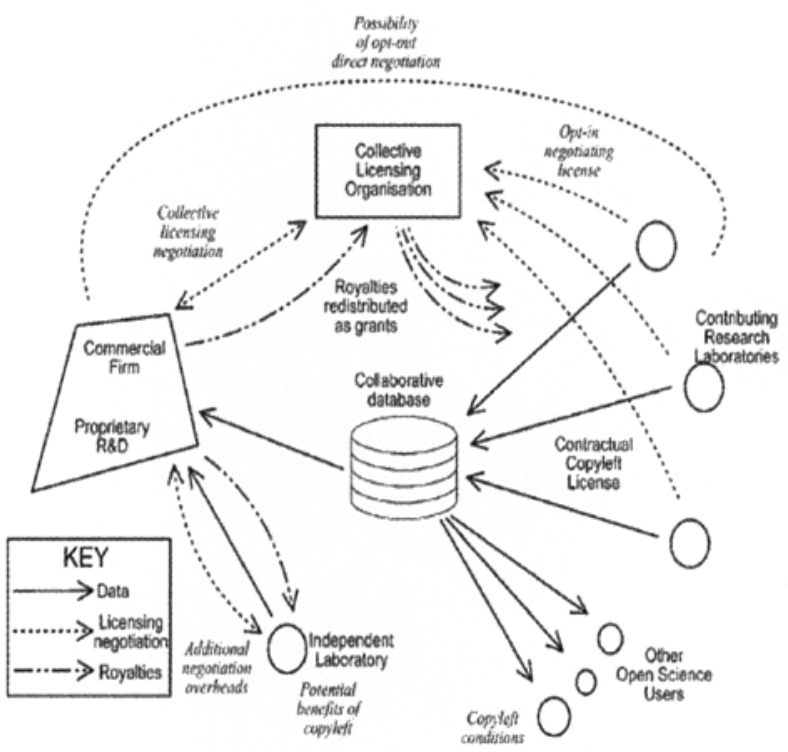

Figure 2: A two-tiered system for data sharing based on the transfer of property rights to ${ }^{8}$ 
Under these conditions, the OECD working group advised that different contractual conditions for access to the database be adopted for commercial and noncommercial use. In this model, which is analogous to the dual licensing model employed by some software developers, ${ }^{9}$ non commercial redistribution is permitted by a copyleft license ${ }^{10}$, under the usual conditions of mentioning the source of the data (guarantee of credit). Commercial use of the data is permitted only when a specific contract that includes restrictions on this commercial use and specifies a license fee has been negotiated. Negotiating these ownership licenses could be the task of a collective licensing organisation administering the database (Figure 2).

\subsubsection{Organising the licensing of data through agreed contractual templates}

The proposals for a dual licensing model for neuroinformatics data sharing is in many respects similar to the conditional deposits model suggested by Reichman and Uhlir in the broader context of the sharing of governmental funded scientific research data. However, they consider a negotiated solution, rather than having recourse to a collective licensing organisation (Figure 3).

As Reichman and Uhlir point out, because of the potential problems of leakage (moral hazard) and enforcement (accountability) in collective licensing organisations, the data providers may very well balk at participating in collectively managed collaborative databases (Reichman and Uhlir 2003, p.433). Moreover, in the case of commercially valuable data, they might prefer to retain some autonomy in negotiating the terms of their private transactions and/or they might want to impose restrictions on the uses of the data for commercial purposes. Under such conditions, data sharing on the basis of a multilateral negotiated agreement is to be preferred. The core of Reichman and Uhlir's proposal is a common agreement on the contractual templates to be used in transactions with public or private partners. To succeed, 'these templates must be acceptable to the universities, the funding agencies, the broader scientific community, and the specific sub-committees - all of whom must eventually weigh in to ensure that academics themselves observe the norms that they would thus have collectively implemented' (ibid., p. 439).

\footnotetext{
9 See, for example, the successful MySQL database software

${ }^{10}$ Under a copyleft regime for software, all users have the right to modify and adopt the program freely, upon the condition that their resulting development is also made freely available for use and further adaptation. The proposal of the OECD working group is to use the same license provision for non commercial use of databases.
} 
The Institutional Dynamics of Sharing Biological

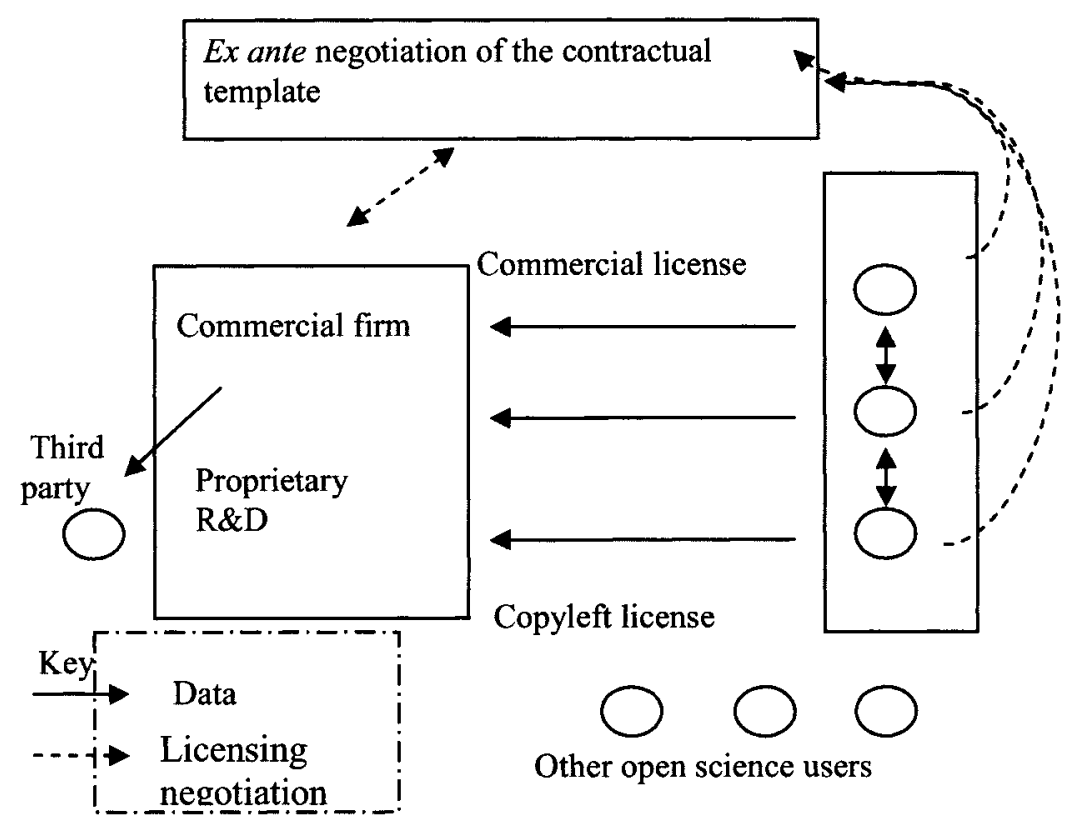

Figure 3: Two-tiered system for data sharing based on a multilateral agreement on contractual template

\section{Enhancing dynamic efficiency}

In Section 1 we analyzed different institutions for information sharing from the point of view of optimal institutional design. Indeed the rationale was to look for the optimal institutional design given a certain transaction situation. Nevertheless, as has been shown elsewhere, this static analysis of institutional choice has some important weaknesses (Young 2001, Brousseau 2000). In particular, in changing and controversial social contexts, no ex ante evaluation of the best possible institutional solution can be made. Further, even in the cases where one reasonably can make a trade off between the different "second-best" options, one still has to consider how to change the existing institutions in the direction of the new collaborative arrangements. For this reason several authors (Ostrom 1998, Eggerston 1990, Denzau and North 1994, Knight and North 1997, Rai 1999, Brousseau 2005) have tried to address specifically the problem of institutional dynamics. In particular, analysis has focused on the creation of incentives for institutional adaptation and innovation through reflexive processes of social learning and institutional 
experimentation. I have illustrated this distinction between static and dynamic analysis in Table 3.

\begin{tabular}{|l|l|l|}
\hline & Addressed problem & $\begin{array}{l}\text { Role of } \\
\text { institutions }\end{array}$ \\
\hline $\begin{array}{l}\text { Static } \\
\text { efficiency }\end{array}$ & $\begin{array}{l}\text { Alignment of the economic coordination } \\
\text { structures to the transaction situation }\end{array}$ & $\begin{array}{l}\text { Optimisation of } \\
\text { transaction costs } \\
\text { through the (ex } \\
\text { ante) definition } \\
\text { of property } \\
\text { rights and (ex } \\
\text { post) } \\
\text { supervisory } \\
\text { mechanisms } \\
\text { ensuring } \\
\text { cooperative } \\
\text { behaviour }\end{array}$ \\
\hline $\begin{array}{l}\text { Dynamic } \\
\text { efficiency }\end{array}$ & $\begin{array}{l}\text { Path dependent evolution of existing } \\
\text { institutions, incremental transformation } \\
\text { processes of institutions. }\end{array}$ & $\begin{array}{l}\text { Sustaining the } \\
\text { dynamics of } \\
\text { innovation and } \\
\text { adaptation } \\
\text { through learning } \\
\text { and competitive } \\
\text { selection } \\
\text { amongst a } \\
\text { plurality of } \\
\text { social valves }\end{array}$ \\
\hline & & \multicolumn{2}{|c|}{} \\
& &
\end{tabular}

Table 3: Some key features of the difference between analysis of static and dynamic efficiency ${ }^{11}$

Especially in a situation of complex global interlinkages, such as characterises the microbiological information commons, dynamic efficiency plays a key role in enhancing the effectiveness of governance arrangements. The viability of collaborative databases depends crucially on the enforcement of norms of cooperation and the presence of learning mechanisms that allow the emergence of common beliefs. For example, the introduction of new rules for intellectual property rights has lead to a decline in the sharing ethos of science communities, and hence new cooperative networks and norms have had to be developed to sustain the practices of data sharing. In other cases, important changes have occurred at the level of the beliefs of different actor communities. For example, the new concepts that

11 Source: adapted from Dedeurwaerdere (2005). 
resulted from the work of the OECD working group on the relationship between bioinformatics and biodiversity were some of the key factors that allowed innovative partnerships to emerge between institutions having very different institutional policies at the outset.

In the field of institutional economics two important families of models have been developed for studying dynamic efficiency (Dedeurwaerdere 2005, pp.481484). A first family of models, which can be called 'structural models', focuses on a set of cases where particular configurations of rules and norms have lead to sustainable outcomes and enhanced welfare (Ostrom 1986). From an in-depth analysis of the conditions for success of these configurations a set of 'design rules' can be defined for creating institutional incentives for enforcing norms of cooperation. A second family, which can be labelled 'process models', focuses on the historical processes of continual change in rules (North 1990). Here the aim is to analyse the conditions that have lead to an enduring dynamic interaction between rules and changing beliefs in a given transaction situation. Through this analysis, the goal is to identify any bottlenecks in the learning processes that have lead to suboptimal outcomes in the past (such as restricting the learning process to established interests or the absence of a clear institutional mandate for learning).

The distinction between these two types of models allows the double dynamic role of governance institutions in influencing the social context of the collaborative database initiatives to be identified: first, their role in enforcing the norms of cooperation within the network of actors in the self-governing collective arrangements; and second, their role in building a process of social learning geared towards common beliefs among different actor networks and institutional settings. In this section, I will argue for the importance of considering these two types of dynamic efficiency in the building of practical proposals for a more reflexive design of the information commons.

\subsection{Organizing reflexive feedback from the actors on the institutional rules}

The introduction of new rules governing the intellectual property rights resulting from governmentally funded basic research have had a major impact on the norms of the science community. First, the norms that characterise fundamental research (such as common cumulative heritage, independent inquiry and originality (Merton 1973)) now have to compete with norms of exclusion and profit raising that have gained ground in the research community. An oft-cited example is Blumenthal et al.'s (1997) survey of life science academics, showing that participation in industryfunded research is associated with a delay in publication of research results by more than six months, because of intellectual property rights' issues.

The design of self-governing collective action institutions also has to take into account this changing social context. Under conditions of changing norms, any proposed set of institutional rules will affect the norms of the actors concerned; hence a linear relationship between a given set of rules and their outcomes can no 
longer be established. Under such conditions, comparative analysis has proved useful in studying the interaction between rules and their social context. As has been shown by research on common pool resources, focusing on effective 'social possibilities', where particular configurations of rules and norm have lead to sustainable outcomes and enhanced welfare, allows a set of robust design rules that are common to the successful endeavours to be defined. This structural methodology has also proved useful in the field of knowledge commons. In their seminal research, Hess and Ostrom $(2003,2005 a)$ showed that some features of this comparative analysis could be adapted for the study of the new digital knowledge commons. For instance, a report by the Research Library Group and the Online Computer Library Center, cited by Hess and Ostrom in their initial paper (2003), defines the required actions and rules for creating successful cooperation in the particular case of trusted digital libraries as being: (1) audibility, security, and communication; (2) compliance and conscientiousness; (3) certification, copying controls, and rule following; (4) backup policies and avoiding, detecting and restoring lost/corrupted information; (5) reputation and performance; (6) agreements between creators and providers; (7) open sharing of information about what is being preserved and for whom; (8) balanced risk, benefit, and cost; (9) complementarity, cost-effectiveness, scalability and confidence; and (10) evaluation of the system's components (ibid., p.144). These principles illustrate the design rules for enhancing cooperative behaviours and system resilience that are needed to sustain the global knowledge commons. Further comparative analysis is needed to gain insights into the specific design characteristics of data sharing in the digital environment.

One of the most sophisticated attempts to do this in the field of microbiological commons, is the empirical research of Arti Rai on intellectual property rights and the norms of science (Rai 2005). In her comparative research on data-sharing initiatives, Rai has shown the importance of reputational benefits as a key factor in determining the viability of these initiatives in a highly protectionist intellectual property environment. More precisely, relying on cross-field case studies in both opensoftware and biotechnology, her analysis showed that the chances of self-governing collective action initiatives for data sharing succeeding is highest where reputational effects are large and the capital input that is required for participating in the data sharing is very small. A case in point is the success of open-source software. In this case, the transaction costs for establishing reputional mechanisms remain low, because the information inputs of large numbers of individuals can be readily evaluated and integrated in the on-line environment. At the same time, volunteers do not have to invest any resources other than time in participating.

An important example of data sharing in the field of microbiology that complies with this model is the Public Sector Intellectual Property Resource for Agriculture (PIPRA) consortium for agricultural biotechnological research for developing countries $^{12}$. In this consortium, 21 non-profit institutions (mainly universities) and the US Department of Agriculture have committed themselves to articulating a nonrestrictive licensing policy for research oriented towards the developing world. One important policy tool that this consortium aims to promote is the systematic preservation of the availability of intellectual property rights for research related to

12 www.pipra.org (last visited July 2005). 
developing countries when licensing technologies to the private sector. According to Rai, this is a good example of a case where the expected reputational benefits outweigh the potential financial loss from data-sharing policies. Indeed, as stated by Roger Beachy, one of the initiators of the consortium, '[a]lthough there may be a modest financial cost of taking such a position, the potential benefits in terms of regaining public trust, and ultimately of deploying technologies where they may be needed most, far outweigh the financial or opportunity costs' of low commercial value (Beachy 2003, p.473). A related example in the field of biotechnology research is a consortium for marker-assisted wheat breading (Rai 2005, p.301). This consortium manages a website that contains research protocols and marker sequences that can be freely accessed and used by researchers all over the world.

These cases of low commercial value present the clearest similarities to the free software model of data sharing. By extension, reputational benefits could also enable data sharing, where there is great uncertainty over the commercial-value of research output into microbiology. Here the paradigmatic case is the Human Genome Project, where academic scientists, working with the US National Institutes of Health, agreed not to seek property rights to raw human genome sequence data. As argued by Rai, the presence of potentially high reputational benefits for the universities involved played an important role in the success of the Human Genome Project. Moreover, in this context of uncertain, but potentially high, value, the likelihood of gain from strategic behaviour is lower than in the context of research of high commercial value. By contrast, another initiative for data sharing, the multilateral agreement on nonrestrictive material transfer agreements between Technology Transfer Offices, UBMTA $^{13}$, failed to generate the expected benefits. In this case, unlike the scientists working on the Human Genome Project, the university technology transfer offices were motivated in significant part by the desire to increase licensing revenue. Hence reputational effects played only a minor role.

\subsection{Building common understanding}

A second family of models for studying the dynamic relationships between rules and the social context focuses on the historical processes of sustained adaptation of rules (North 1990). Here the aim is to analyse the conditions that have lead to an enduring learning process.

Process of social learning about conflicting beliefs also play a key role in the field of microbiological commons. Some particularly difficult issues which are the subject of continuing discussion are the protection of traditional knowledge, the regulation of pre-CBD (the Convention of Biological Diversity) resources, and the most appropriate transmission and identification protocols to be used in data sharing. For instance, on the issue of pre-CBD resources, some people argue that the rules governing the flow of resources should focus on modern germplasm exchange,

13 UBMTA stands for the Uniform Biological Material Transfer Agreement. This is a voluntary agreement reached in 1995 between university technology transfer offices from more than 100 institutions in the USA. However its success was limited. 
related to contemporary needs and interests, and that these rules cannot apply to flows of resources from the pre-genomic era which no longer exist (Fowler 2004, p.51). Others point to the importance of returning equity to countries of origin, especially in the case of biogenetic resources associated with traditional knowledge, or, more simply, to the potential usefulness of the repatriation of certain resources to the provider countries as a means of capacity building or strengthening the links between scientific institutions in developing and developed countries (Muller 2004, pp.38-40). On the issue of transmission protocols for data sharing, the discussion about the appropriate standard for global data sharing among competing systems (such as Darwin Core or ABCD) is also a complex issue, especially because of the variety of different types of resources that can be exchanged.

The adoption, by a sufficiently broad range of economic actors, of common institutional rules for data sharing will depend on organising learning processes that supersede these antagonistic beliefs about the most appropriate action. Within new institutional economics, the influence of beliefs on the behaviour of economic actors has been modelled in terms of their influence on the change in the perception of action opportunities. In terms of rational action theory, beliefs influence the actors' behaviour through modifying the weights attached to the different outcomes in the pay-off matrix. According to North (1995, pp.25-26), dynamic efficiency in a context of changing beliefs is determined by a flexible institutional matrix that organises learning process in a way that allows the economic actors to perceive new action opportunities. These new perceptions in turn create an incentive for the actors to engage in a process of 'incremental modification of economic and political rules' (ibid., pp.23-24). For example, organising a learning process between private companies and local communities on the role of traditional knowledge in local innovation can help to overcome misunderstanding and opportunistic behaviour and lead to new partnerships being developed around issues of common concern.

However, in a situation of controversy over the validity of the antagonistic beliefs, it is not possible to decide ex ante which learning process will produce the optimal outcomes. Hence, a better way of studying the dynamic efficiency of changes in beliefs is to compare historically successful cases of dynamic interaction between rules and beliefs. This method is at the heart of North's study of economic history, and has more recently also been applied successfully in the study of the regulation of climate change and pollution control (Haas and McCabe 2001, Haas 1990). Examples of successful design principles that emerged from these studies are the independence of the learning process from the policy process, the importance of an institutional mandate in the learning community (ibid.) and the participation of the widest possible community in the learning process, so as to prevent vested interests blocking progress (North 1995).

An interesting example of a successful case of learning within the field of microbiological commons is the role of the OECD in the establishment of the Global Biodiversity Facility (GBIF). The idea of creating the GBIF developed from the discussions organised in the context of the OECD Megascience Forum ${ }^{14}$, an intergovernmental forum where scientific ideas can be exchanged and consensus reached on the best way either to acquire new knowledge or to take advantage of a

14 Now called the OECD Global Science Forum. 
significant scientific development (James 2002, p.5). The discussions that led to the GBIF took place in the Working Group on Biological Informatics between April 1996 and September $1998^{15}$ and allowed new ideas integrating the concerns of two related communities (the established conservation community on the one hand and the emerging bioinformatics community on the other) to develop. As a result of the recommendations of this Working Group, an Interim Steering Committee was set up in 1999 under the auspices of the OECD ministers, which finally lead to the establishment of the GBIF in autumn 2001.

The learning process that led to the GBIF can be characterised by: (1) the existence of an explicit institutional mandate, through the OECD, for developing new knowledge among different communities; and (2) a certain degree of independency of the learning community from the policy process in the different member countries ${ }^{16}$. The criterion of independence seems to be very important in the case of the GBIF. Indeed, the initiators of the GBIF insisted on the importance of establishing its secretariat as an autonomous legal entity. This secretariat has been given the task of elaborating its own working programs for coordinating data sharing in the field of biodiversity. The GBIF recently enlarged its operations to civil society organisations by opening its data portal to the dissemination of the results of the yearly bird count in New York and Berlin's Tiergarten.

The real stake however, in the field of microbiological commons, is to establish learning processes that can generate a common understanding of the issues involved in organising the conditions for downstream use of data and/or the related biological resources. The GBIF is an interesting example of a learning process, because it is an adaptive organisation and provides some insights into the design rules for dynamic efficiency. However, as stated earlier, it leaves both the ownership rights and the decision rights on the conditions of use of the data and/or the resources to the original data providers. Some institutional learning on the issue of downstream applications is already occurring in other organisations, for example in the 1997-98 Working Group of the US National Institutes of Health (NIH) on the transfer of proprietary research tools in biomedical research. However this and other examples are only organised on an ad hoc basis. More research is needed on the functioning of successful and unsuccessful instances of enduring processes of interaction between

15 The report was published in January 1999. In it, the Subgroup on Biodiversity Informatics of the Working Group on Biological Informatics recommended the establishment of an international coordinating body and a new data network called the Global Biodiversity Information Facility.

16 These characteristics are also found in other well-documented historical examples of institutional learning, such as climate change, where the Villach Group played a key role in the organisation of an enduring learning process. This group was composed of international climate scientist who worked on the basis of an institutional mandate from the UNEP Secretariat in the wake of the 1992 Rio Conference. In 1993 the Villach Group was transformed into an intergovernmental panel. It became increasingly susceptible to policy pressure and lost some of its credibility in the second half of the 1990s (Haas and McCabe 2001). 
beliefs and rules, so that we can adapt our knowledge of design rules from other fields to the field of microbiological commons.

\section{Conclusion}

The aim of this paper is to contribute to building a framework for reflexive governance in the field of the information society. The hypothesis is that new institutional economics as an interdisciplinary research program can provide some of the necessary tools for this framework and help us to understand how to embed in institutions of regulation the reflexive feedback of actors and users on the social challenges of the new technologies.

In this paper, we developed a specific case study on the building of a microbiological commons, because of the leading role of this field in the development of institutions for reflexive involvement of the actors and users on the social challenges of the new technologies. Our focus in this case study is on the way this reflexivity can be embedded in the institutions that are created by the concerned actors to organize global information sharing.

In the first section, I have argued for the importance of considering the microbiological information commons both as a public good and as a common pool resource. This point is important in order to understand the importance of selfgoverned actor initiatives for building and preserving the information commons, beyond pure government initiative or market rule. As an illustration, I considered more closely the successful endeavours of the Global Biodiversity Information Facility and the proposals for a two-tiered regime for governing the conditions of follow-on use of the data and related biological resources.

The institutional conditions analysed in the first section already show the importance of the involvement of the actors and users in the design of institutions in the field of global information sharing. In the second section, we use these results to analyse the problem of institutional dynamics. Our analysis in this second section has shown that institutional innovation and adaptation can be organized through a double reflexive mechanism. A first mechanism, which has been illustrated through the case studies on the human genome project, open software and scholarly information, focuses on the embedding of institutional rules in self-organised cooperative actors' networks. Reflexivity is organized through a feedback of these actor networks on the proposed institutional change. A second mechanism focuses on the long term process of change in the background understandings of different actor networks and institutional settings. Here reflexivity is organised through an institutional setting that favours the learning of new common understandings and normative frameworks, such as in the case of the OECD working group that has lead to the creation of GBIF.

The main argument of the paper is the importance of taking into account the dynamic interaction between the creation of new institutions and the changing social context of norms and beliefs. As I attempted to show, this implies going beyond the problem of static efficiency, which is concerned with the allocation of a set of institutional rules to obtain the desired behavioural outcomes. Indeed, there is no $e x$ ante optimal solution for institutional design in situations of changing norms and 
controversial beliefs. However, through comparative research, a robust set of design rules can be defined for embedding reflexivity in institutions, enforcing norms of cooperation and fostering the emergence of common understandings.

\section{References}

Arzberger, P., Schroeder, P., Beaulieu, A., Bowker, G., Casey, K., LaAksonen, L., MoOrman, D., Uhlir, P. AND Wouters, P., 2004. Promoting Access to Public Research Data for Scientific, Economic, and Social Development. Data Science Journal, 3, 135-152.

BEACHY, R., 2003. IP Policies and Serving the Public. Science, Vol. 299, p.473.

BENKLER, Y., 1998. The Commons as a Neglected Factor of Information Policy. Remarks at the Telecommunications Policy Research Conference (Sept. 1998), available at http://www.benkler.org/commons.pdf (last visited July 2005).

Blumenthal, D., Campbell, E.G., Anderson, M.S., Causino, N. and louis, K.S., 1997. Withholding Research Results in Academic Life Sciences: Evidence From a National Survey of Faculty. The Journal of the American Medical Association, Vol. 277 (15), 1224-1228.

BRousseau, E., 2000. Processus évolutionnaires et institutions: quelles alternatives à la rationalité parfaite?. Revue économique, Vol. 51 (5), 1185-1213.

Brousseau, E., 2005. Multilevel Governance of the Digital Space: Does a 'Second Rank' Institutional Framework Exist?. Working paper at www.brousseau.inf (last visited August 2005).

DEDEURWAERDERE, T., 2005. From bioprospecting to reflexive governance. Ecological Economics, vol.53(4), 473-491.

DEDEURWAERDERE, T., 2006a. Databases, biological information and collective action. In : Jacques BERLEUR, Markku I. NURMINGEN, John IMPAGLIAZZO, Social Informatics Society for All?. In Remembrance of Rob Kling, Springer, 2006, pp. 159-170.

DEDEURWAERDERE, T., 2006b. The institutional economics of sharing biological information. International Social Science Journal, Spring 2007, forthcoming.

Demsetz, H., 1967. Towards a Theory of Property Rights. American Economic Review, Vol. 62, 347-359. 
DenzaU, A.T. AND NORTH, D.C., 1994. Shared Mental Models: Ideologies and Institutions. Kyklos, Vol. 47, 3-31.

ECKersley, P., Egan, G.F., Amari, S., Beltrame, F., BenNett, R., et al., 2003. Neuroscience Data and Tool Sharing. Neuroinformatics Journal, Vol. 1 (2), 149165.

EgGerston, T., 1990. Economic Behavior and Institutions, Cambridge University Press, Cambridge.

FowlER, C., 2004. Diversity and Protectionism. Use of Genebanks: Trends and Interpretations. Presentation made at the World Food Day 16 october 2004, Basel, $49-51$.

GEVERS, D., COHAN, F.M., LAWRENCE, J.G., SPRATT, B.G., COEYNE, T., FEIL, E.J., STACKEBRANDT, E., VAN DE PEER, Y., VANDAMME, P., THOMPSON, F.L. and SWINGS, J., submitted. Reevaluating prokaryotic species. Nature Reviews Microbiology.

HAAS, P., 1990. Saving the Mediterranean, Columbia University Press, New York.

HAAS, P.M. AND MCCABE, D., 2001. Amplifiers or Dampeners: International Institutions and Social Learning in the Management of Global Environmental Risks. In: ClaRK, W.C., JÄGER, J., VAN EIJNDHOVEN, J. AND DICKSON, N.M., Learning to Manage Global Environmental Risks. MIT Press, Cambridge (MA), Vol. 1, 323348.

Hess, C. AND OSTROM, E., 2003. Ideas, artifacts and facilities. Information as a common-pool resource. Law and contemporary problems, Vol. 66(1/2), 111-146.

JAMES E. 2002, Establishing International Scientific Collaborations: Lessons learned from the Global Biodiversity Information Facility, Report to the Sixth Meeting of the OECD Global Science Forum, January 2002.

Kaul, I., Conceiçao, P., Le Goulven, K. and Mendoza, R.U., eds., 2003. Providing Global Public Goods. Managing Globalization. Oxford University Press, New York/Oxford.

KNIGHT, J. AND NoRTH, D., 1997. Explaining Economic Change: The Interplay Between Cognition and Institutions. Legal Theory, Vol. 3, 211-226.

LESSIG, L., 1999. Code and the Commons. Keynote Address at the Conference on Media Convergence, Fordham University Law School (9 February, 1999), available at http://cyber.law.harvard.edu/works/lessig/fordham.pdf (last visited July 2005).

MERTON,R.K., 1973. The Normative Structure of Science. In: STORER, N.W., ed., The Sociology of Science. University of Chicago Press, Chicago, 267-278. 
MULLER, M.R., 2004. An Analysis of the Implementation of Intellectual Property Rights on the Global Biodiversity Information Facility. Working paper of the Global Biodiversity Information Facility, Copenhagen.

NORTH, D.C., 1990. Institutions, Institutional Change and Economic Performance. Cambridge University Press, Cambridge.

NORTH, D.C., 1995. The New Institutional Economics and Third World Development. In: HARRIS, J., HUNTER, J. AND LEWIS, C.M., eds., The New Institutional Economics and Third World Development. Routledge, London/New York, 17-26.

OECD, 2001. Biological Resource Centres. Underpinning the future of life sciences and biotechnology. OECD Science and Information Technology, Vol. 7, 1-68.

OLDHAM, P., 2004. Global Status and Trends in Intellectual Property Claims: Genomics, Proteomics and Biotechnology. Centre for Economic and Social Aspects of Genomics.

Ostrom, E., 1986. An Agenda for the Study of Institutions. Public Choice, Vol. 48, $3-25$.

OSTROM, E., 1998. A Behavioral Approach to the Rational Choice Theory of Collective Action. American Political Science Review, Vol. 92(1), 1-22.

Ostrom, E. and HESS, C. 2006. A Framework for analyzing the knowledge commons. In : C. Hess, C. and Ostrom, E., eds, Understanding Knoweldge as a Commons, Cambridge, MA: MIT Press, 41-82.

OSTROM E. AND C. HESS., 2005b. A Framework for Analyzing Governance and Collective Action in the Microbiological Commons. International Social Science Journal, Spring 2007, forthcoming.

RAI, A.K., 1999. Regulating Scientific Research: Intellectual Property Rights and The Norms of Science. Northwest University Law Review, Vol. 77, 77-152.

RAI, A.K., 2005. Proprietary Rights and Collective Action: The Case of Biotechnology Research with Low Commercial Value. In: MASKUS, K. AND REICHMAN, J., eds., International Public Goods and Transfer of Technology. Cambridge University Press, Cambridge, 288-306.

RAI,A.K. AND EISENBERG, R.S., 2003. Bayh-Dole Reform and the Progress of Biomedicine. Law and Contemporary Problems, Vol. 66 (1/2), 289-314.

REICHMAN, J., 2002. Database Protection in a Global Economy. Revue Internationale de Droit Economique, 2-3, 455-504. 
ReICHMAN, J. AND UhLIR, P.F., 1999. Database Protection at the Crossroads: Recent Developments and Their Impact on Science and Technology. Berkeley Technology Law Journal, 14, Vol. 793, 799-821.

REICHMAN, J. AND UhLIR, P.F., 2003. A Contractually Reconstructed Research Commons for Scientific Data in a Highly Protectionist Intellectual Property Environment. Law and Contemporary Problems, Vol. 66, 315-440.

Schlager, E. And Ostrom, E., 1993. Property Rights Regimes and Coastal Fisheries: An Empirical Analysis. In: ANDERSON, T.L. AND SIMMONS, R.T., eds., The Political Economy of Customs and Culture: Informal Solutions to the Commons Problem. Rowman and Littlefield, Lanham (MD), 13-41.

SMith, R., ThorsteIndotTir, H., DAAR, S.A. AND Singer, P.A., 2004. Genomics Knowledge and Equity: A Global Public Goods Perspective on the Patent System. Bulletin of the World Health Organization, 384-389.

Stiglitz, J., OrSZAG, P.R. AND OrSZAG, J.M., 2000. The Role of Government in a Digital Age. Report for the Computer and Communications Industry Association, United States.

Williamson, A.R., 1998. Access to Data and Intellectual Property. Patents and Technology Transfer. Public Affairs Report of the American Society for Microbiology, pp. 9-11

YounG, O., 2001. The Behavioral Effects of Environmental Regimes: CollectiveAction vs. Social-Practice Models. International Environmental Agreements: Politics, Law and Economics, Vol. 1, 9-29. 